\title{
New Aspects of Occurrence and Removal of Emerging Pollutants
}

\author{
Joanna Karpińska (D) and Urszula Kotowska * \\ Department of Analytical and Inorganic Chemistry, Faculty of Chemistry, University of Bialystok, \\ Ciołkowskiego 1K Str., 15-245 Bialystok, Poland; joasia@uwb.edu.pl \\ * Correspondence: ukrajew@uwb.edu.pl; Tel.: +48-85-738-81-11
}

Citation: Karpińska, J.; Kotowska, U. New Aspects of Occurrence and Removal of Emerging Pollutants. Water 2021, 13, 2418. https:// doi.org/10.3390/w13172418

Received: 30 August 2021

Accepted: 31 August 2021

Published: 3 September 2021

Publisher's Note: MDPI stays neutral with regard to jurisdictional claims in published maps and institutional affiliations.

Copyright: (c) 2021 by the authors. Licensee MDPI, Basel, Switzerland. This article is an open access article distributed under the terms and conditions of the Creative Commons Attribution (CC BY) license (https:// creativecommons.org/licenses/by/ $4.0 /)$.
Emerging pollutants (or contaminants) (EPs) are a wide group of organic and inorganic chemicals present in the environment as a result of human activity. Their sources are everyday household activities, protection of human and animal health, as well as in industrial and agricultural production [1]. Most of these compounds have been present in the environment for decades but their detection has been made possible by the development of highly sensitive analytical techniques. The group of emerging pollutants includes, among others, human and animal pharmaceuticals, personal care products, surfactants, and flame retardants, in addition to compounds used in the production of plastics, hormones and steroids, pesticides and fertilizers, nanoparticles, microplastics, and trace metals. All EPs have a potentially negative impact on living organisms and on the course of environmental processes. Endocrine disruption and both carcinogenic and mutagenic effects on animals and human have been proven for many compounds. Young organisms are particularly sensitive to harmful effects of EPs [2,3].

The most important source of EPs released into the environment is municipal and industrial wastewater. Due to the limited effectiveness of traditional purification processes used in wastewater treatment, these pollutants are continuously discharged into water and soil, causing a chronic impact on ecosystems. Therefore, the protection of the biodiversity and health of organisms requires searching for efficient processes of removing EPs from polluted waters. Many methods have already been described in the literature and new technologies are increasingly used in practice [4]. Advanced wastewater treatment technologies of EPs removal usually use chemical (transformation into simple, non-toxic compounds) or physical (transfer of pollutants to another medium) methods. However, doubts are raised by the economic sustainability and the overall environmental benefits of these advanced technologies, in connection with the consumption of large amounts of energy or the production of new waste [5].

This Special Issue presents new aspects concerning the occurrence of emerging pollutants in wastewater and other water samples, as well as selected methods for their removal. The Water Special Issue consists of six articles, two of which are reviews and four that present the results of the experiments carried out. The occurrence characteristics were presented in particular for compounds from the group of pharmaceuticals and personal care products (PPCPs) [6]. Other published studies focused on the removal of EPs by biological (phytoremediation) [7,8] as well as chemical (oxidation) [9] and physical (sorption and reverse osmosis) methods [10,11]. Twenty authors from five countries (Poland, Korea, Argentina, Portugal, and Peru) comprised their contribution in the preparation of the published papers. The main achievements of the scientific articles included in this Special Issue are presented below.

\section{Pharmaceutical and Personal Care Products in Different Matrices: Occurrence, Pathways, and Treatment Processes}

This review, based on 153 scientific articles from the last 15 years, addresses the issue of the presence of EPs from the PPCPs group in aqueous and biological samples [6]. The 
collected data indicate the widespread presence of pollutants in samples from all over the world, at concentrations ranging from $\mathrm{ng} / \mathrm{L}$ to $\mu \mathrm{g} / \mathrm{L}$. The most commonly detected compounds revealed to be non-steroidal anti-inflammatory drugs as well as carbamazepine and caffeine. The presence of PPCPs registered in the tissues of plants and animals, in addition to the bioaccumulation of some compounds in food chains, is disturbing. The authors of the work [6] indicate an insufficient number of studies on the presence of PPCPs in living organisms as well as its ecotoxicity.

\section{Insights into the Use of Phytoremediation Processes for the Removal of Organic Micropollutants from Water and Wastewater: A Review}

This article deals with the use of plants to remove EPs from polluted waters and shows phytoremediation as a pro-ecological and low-cost method [7]. The review was based on 120 papers from about the last dozen years. The work summarizes both the research carried out in laboratory and in field conditions with the use of model EPs' solutions and real wastewater. The conducted literature analysis shows that the effectiveness of phytoremediation ranges from a few to over $99.9 \%$ and depends very strongly on the structure of the compound to be removed, the plant species, and the conditions of the process. The authors indicate that the nature of the described method makes it especially recommended for developing countries.

\section{Variations in the Phytoremediation Efficiency of Metal-Polluted Water with Salvinia biloba: Prospects and Toxicological Impacts}

The use of Salvinia biloba, the common aquatic plant, to remove trace amounts of metals from water samples has been investigated in detail in this experimental study [8]. The efficiency of metal removal in laboratory conditions reached over $95 \%$ during a 48 -hour exposure. The accumulation of metals in the plant tissues caused oxidative stress expressed, inter alia, in changes in the plant morphology and in the concentrations of both chlorophylls and carotenoids in leaves. The presented results indicate the possibility of using S. biloba as a bioindicator.

\section{Kinetics and Mechanistic Studies of Photochemical and Oxidative Stability of Galaxolide}

The removal of galaxolide, a commonly used compound from the group of synthetic polycyclic musks, by photochemical and chemical oxidation is presented in this article [9]. Studies have shown that galaxolide is a photolabile compound and is easily degraded under the influence of light as well as chemical factors. UV radiation increases the rate of this compound's degradation by six times in comparison to the simulated sunlight. The most important role in the oxidation of galaxolide is played by hydroxyl radicals and the degradation process includes ring opening, $\mathrm{OH}$ addition, and metathesis.

\section{Physicochemical Interactions in Systems C.I. Direct Yellow 50-Weakly Basic Resins: Kinetic, Equilibrium, and Auxiliaries Addition Aspects}

This work concerns the use of adsorption to remove dye from wastewater from the textile industry [10]. The use of weakly basic anion exchangers for this purpose was subjected to physicochemical and thermodynamic tests. Sorption has proven to be highly effective over a wide $\mathrm{pH}$ range and in the presence of chemicals that are components of industrial wastewater. A problem in the practical use of sorption methods is the utilization of used sorbent, the regeneration of which is ineffective in the case of many dyes. The undeniable advantages of sorption, which are confirmed in this article, are the higher effectiveness than in the case of other methods and the multitude of available sorption materials.

\section{The Identification of Fouling in Reverse Osmosis in the Treatment of Water with Petroleum Substances}

This work presents the use of reverse osmosis to remove aromatic compounds from surface waters and focuses on both resistance-in-series analysis and fouling mechanism 
identification [11]. The process of reverse osmosis is the forced diffusion of ions or molecules through a semi-permeable membrane from a solution with a higher concentration to the solution at a lower concentration due to the increased pressure forcing the particles to pass through the membrane. The fouling of the membrane pores is a fundamental problem in the practical use of reverse osmosis. The study of pore blocking mechanisms helps to establish the conditions for the effective use of this method in water and wastewater treatment technologies.

Author Contributions: The two authors made equal contributions to this editorial. Both authors have read and agreed to the published version of the manuscript.

Funding: This work was supported by the Polish National Centre of Science, with the grant 2019/33/B/NZ8/00012, and by the Polish Ministry of Science and Higher Education, with the grant MNiSW/2020/321/DIR.

Data Availability Statement: No new data were created or analyzed in this study. Data sharing is not applicable for this article.

Conflicts of Interest: The authors declare no conflict of interest.

\section{References}

1. Taheran, M.; Naghdi, M.; Brar, S.K.; Verma, M.; Surampalli, R.Y. Emerging Contaminants: Here Today, There Tomorrow! Environ. Nanotechnol. Monit. Manag. 2018, 10, 122-126. [CrossRef]

2. Gonsioroski, A.; Mourikes, V.E.; Flaws, J.A. Endocrine Disruptors in Water and Their Effects on the Reproductive System. Int. J. Mol. Sci. 2020, 21, 1929. [CrossRef]

3. Pironti, C.; Ricciardi, M.; Proto, A.; Bianco, P.M.; Montano, L.; Motta, O. Endocrine-Disrupting Compounds: An Overview on Their Occurrence in the Aquatic Environment and Human Exposure. Water 2021, 13, 1347. [CrossRef]

4. Rodriguez-Narvaez, O.M.; Peralta-Hernández, J.; Goonetilleke, A.; Bandala, E. Treatment Technologies for Emerging Contaminants in water: A review. Chem. Eng. J. 2017, 323, 361-380. [CrossRef]

5. Gogoi, A.; Mazumder, P.; Tyagi, V.K.; Chaminda, G.G.T.; Kyoungjin An, A.; Kumar, M. Occurrence And Fate Of Emerging Contaminants In Water Environment: A Review. Groundw. Sustain. Dev. 2018, 6, 169-180. [CrossRef]

6. $\quad$ Reyes, N.J.D.G.; Geronimo, F.K.F.; Yano, K.A.V.; Guerra, H.B.; Kim, L.-H. Pharmaceutical and Personal Care Products in Different Matrices: Occurrence, Pathways, and Treatment Processes. Water 2021, 13, 1159. [CrossRef]

7. Polińska, W.; Kotowska, U.; Kiejza, D.; Karpińska, J. Insights into the Use of Phytoremediation Processes for the Removal of Organic Micropollutants from Water and Wastewater: A Review. Water 2021, 13, 2065. [CrossRef]

8. Emiliani, J.; Llatance Oyarce, W.G.; Bergara, C.D.; Salvatierra, L.M.; Novo, L.A.B.; Pérez, L.M. Variations in the Phytoremediation Efficiency of Metal-polluted Water with Salvinia biloba: Prospects and Toxicological Impacts. Water 2020, 12, 1737. [CrossRef]

9. Sokol, A.; Ratkiewicz, A.; Tomaszewska, I.; Karpinska, J. Kinetics and Mechanistic Studies of Photochemical and Oxidative Stability of Galaxolide. Water 2021, 13, 1813. [CrossRef]

10. Wawrzkiewicz, M.; Polska-Adach, E. Physicochemical Interactions in Systems C. I. Direct Yellow 50—Weakly Basic Resins: Kinetic, Equilibrium, and Auxiliaries Addition Aspects. Water 2021, 13, 385. [CrossRef]

11. Piekutin, J. The Identification of Fouling in Reverse Osmosis in the Treatment of Water with Petroleum Substances. Water 2021, 13, 1092. [CrossRef] 